\title{
Lake Users' Perceptions of Environmental Change: Ecosystem Services and Disservices Associated with Aquatic Plants
}

\author{
Louisa E. Wood ${ }^{1,2, *(\mathbb{D}}$, Mialy Z. Andriamahefazafy ${ }^{2,3}{ }^{\mathbb{D}}$, James Guilder ${ }^{1}$, Christian A. Kull ${ }^{3}$ \\ and Ross T. Shackleton ${ }^{3}$ \\ 1 Centre for Environment Fisheries and Aquaculture Science, Weymouth, Dorset DT4 8UB, UK; \\ james.guilder@cefas.co.uk \\ 2 Centre for Blue Governance, University of Portsmouth, Portsmouth PO1 2UP, UK; mialyzanah@gmail.com \\ 3 Institute of Geography and Sustainability, University of Lausanne, 1015 Lausanne, Switzerland; \\ christian.kull@unil.ch (C.A.K.); rtshackleton@gmail.com (R.T.S.) \\ * Correspondence: louisa.wood@cefas.co.uk
}

Citation: Wood, L.E.;

Andriamahefazafy, M.Z.; Guilder, J.;

Kull, C.A.; Shackleton, R.T. Lake

Users' Perceptions of Environmental Change: Ecosystem Services and Disservices Associated with Aquatic Plants. Water 2021, 13, 1459. https:// doi.org/10.3390/w13111459

Academic Editor: Stefano Amalfitano

Received: 13 April 2021

Accepted: 18 May 2021

Published: 22 May 2021

Publisher's Note: MDPI stays neutral with regard to jurisdictional claims in published maps and institutional affiliations.

Abstract: Lake Léman (Lake Geneva), Switzerland, is known to have undergone major environmental change over the last few decades, including changes in the abundance, distribution, and species composition of macrophytic plants (aquatic plants). In this study, questionnaires and key informant interviews were used to assess lake users' perceptions of broad scale environmental change in the lake paying special attention tochanges in the abundance of aquatic plants and the perceived ecosystem services (ES) and ecosystem disservices (EDS) associated with them. In addition, we assessed whether users' perceptions of aquatic plants had an impact on perceived management need. Most respondents (63\%) perceived aquatic plant abundance to have increased over the last 10 years, primarily because of climate change. Aquatic plants were seen to benefit water quality through improved regulation and supporting services, and to provide important habitat and food for fauna. Most EDS associated with increased aquatic plant abundance were categorized as cultural or economic. User perceptions of the ES and EDS associated with aquatic plants affected support for management ( $60 \%$ of respondents supported some form of management), and such information is important for informing environmental decision making.

Keywords: Lake Geneva; environmental management; water weeds; public perception; macrophytes; values

\section{Introduction}

Understanding people's perceptions of the environment and associated benefits and impacts is fundamental for guiding effective environmental management and conservation [1]. People's perceptions can be broadly defined as the manner "wherein people select, organize, interpret, retrieve and respond to the information from the world around them", producing mental impressions and constructions which will ultimately help shape behaviors and actions [2,3]. Individuals' perceptions of the environment are influenced by several factors such as social backgrounds (e.g., political contexts and human value systems, social relationships), personal characteristics (e.g., knowledge, education and age) economic influences and dynamic ecological conditions [1,3]. A robust understanding of individual perceptions is fundamental to mitigate conflict in environmental management, facilitate prioritization and decision-making, and increase the efficacy of stakeholder engagement processes [3]. Perceptions of whether management and governance processes are contextually appropriate can also lead to support or opposition of such actions [1]. Assessing perceived environmental change is also of value as a diagnostic tool, as it allows detection of socio-environmental issues and interlinkages that purely ecological approaches often neglect [4-6] and can promote interdisciplinarity. 
The multifaceted ecosystem services (ES) and human wellbeing framework is increasingly being used in political agendas, management, and research to improve interdisciplinary research, policy and conservation solutions in the face of unprecedented environmental change [7]. However, the incorporation of ES into decision making has focused on biophysical assessments and economic valuation, with little consideration of the perspectives of different stakeholders [8,9]. Where studies have been done, stakeholder perceptions and preferences of ES benefits have been found to be highly variable according to the social and cultural context $[10,11]$ as well as economic contexts $[12,13]$. Further, the interaction between humans and ecosystems are not always positive, resulting in unwanted, unpleasant outcomes, or economic costs to human wellbeing. Following [14], the complementary term "ecosystem disservices" (EDS) are defined as "the ecosystem generated functions, processes and attributes that result in perceived or actual negative impacts on human wellbeing". EDS can be both biotic or abiotic in nature and can range from impacts on people as a result of natural or geophysical hazards (e.g., earthquakes, droughts), to biological hazards (e.g., invasive species) to social hazards (e.g., disease spread) and can affect all spheres of life (e.g., economic, health and cultural). Effective and holistic management of ecosystems requires integrated assessments that consider variation in stakeholder perceptions of ES and EDS [15].

Lake environments are highly important for people and provide a multitude of ES such as nutrient regulation, the provision of fish for food and recreational opportunities [16], but increasingly, they also cause and are affected by EDS, for example, biological invasions [17], eutrophication [18] and disease outbreaks [19] with resulting negative implications for human wellbeing. Lake Léman in Switzerland is no exception. The lake provides a multitude of ES such as water regulation, the supply of drinking water, transport opportunities, supports the livelihoods of fishers and promotes tourism and recreation. At the same time, the lake environment is associated with EDS such as storm hazards and health impacts such as parasitic species like duck lice [20]. Lake Léman was, and remains, threatened by anthropogenic pressures and issues associated with human induced global environmental change, such as pollution, invasive species and climate change [21-25], although the major threats facing the lake environment have changed over the last few decades. A major biotic change taking place in the lake is an alteration in the abundance of macrophytic plant species (hereafter referred to as aquatic plants), which are changing in composition and thought to be proliferating due to increasing summer temperatures and improved water quality, warranting mandated control by the state in places (i.e., see [25]). Due to the perceived increase in aquatic plants in the shallower regions of the lake, where human activity is high (particularly recreation), there is an emergence of different views around their benefits and costs in the popular press (e.g., https:/ / www.tdg.ch/geneve/chaleur-plantes-proliferent-leman/story/13368921 (accessed on 15 July 2020)), which affects lake users' support for ongoing management actions. This suggests there is a need to better understand the dichotomy of views concerning the perceived benefit and costs of these aquatic plants and potential trade-offs with regards to control.

In this study, we aimed to assess lake users' general perceptions of ecosystem change in Lake Léman, Switzerland, and the current major threats to the lake environment. Within this context, we focussed more specifically on assessing users' perceptions of the increasing abundance of aquatic plants, drawing on the ES/EDS frameworks to define perceived benefits and costs. More specifically, we aimed to assess and compare the perceptions of aquatic plants across different lake user groups. In addition, we aimed to assess the relationship between user perceptions and support for management. The results of this study provide insights into local people's perceptions of the socio-ecological impacts of environmental change and the social acceptability of environmental management, which can be used to inform evidence-based adaptive and collaborative management. 


\section{Methods}

\subsection{Study Site}

The study was conducted on the Swiss side of Lake Léman (also known as Lake Geneva). Lake Léman is one of Western Europe's largest lakes at $95 \mathrm{~km}$ in length and up to $13 \mathrm{~km}$ in width and over $300 \mathrm{~m}$ deep. The majority of the lake $\left(345 \mathrm{~km}^{2}\right)$ is under Swiss jurisdiction with the rest $\left(234 \mathrm{~km}^{2}\right)$ under French jurisdiction [25]. Approximately 1.65 million people live in the immediate lake basin (Région Lémanique) as of 2020 (https:/ / ec.europa.eu/eurostat (accessed on 10 March 2021)).

In the 1960s-1980s, the lake was highly threatened by pollution and associated with poor water quality, making it dangerous to even swim in some parts. Pollution from human and agricultural waste, in particular phosphorous, caused vast eutrophication of the lake and had devastating impacts on its fauna and flora. Pollution levels have been better regulated and managed since the 1980s and the lake environment and water quality has improved substantially [26]. The lake, however, faces other current and ongoing threats, for example, due to climate change [21,23,25], sediment changes [24], the impacts of invasive alien species [22,25], and micropollutants [25] all of which affect the lake ecosystem and its use by humans.

In general, the lake has been well monitored for environmental change issues since 1969 with annual reports available on the state of the lake environment (https: / Wwww. cipel.org/publications/rapports-scientifiques/ accessed on 10 March 2021). Monitoring focuses on water temperature, physiochemical quality, biological monitoring of the pelagic zone (mainly algae), and pollutants. These variables tend not to generate different opinions regarding ES and EDS. The long-term dynamics of aquatic plants in the lake are not as regularly monitored (every 10 to 20 years) as other variables [25,27], but changes have been noted. Further, this monitoring mainly focuses on species composition and not total plant biomass or the effects of changes in aquatic plant abundance on the broader ecosystems and people. Therefore, there is great need for further investigations into this.

Currently, Myriophyllum spicatum, Potamogeton perfoliatus, P. pectinatus and P. lucens are the most common native aquatic plants in the lake although there are a further 14 or more species $[25,27]$. There are also invasive alien aquatic plant species (e.g., Elodea nuttallii, Lagarosiphon major) which are increasingly observed $[27,28]$. A key change in the last decade or so is that aquatic plants are growing at greater depths, which is suspected to be driven by progressive warming of the lake's shallow water and improvements in water quality, which may facilitate plant growth [25]. Furthermore, species compositions are changing, for example, P. pectinatus was described as very rare in the middle of the 19th century and was amongst the most abundant species in 1997 but has subsequently decreased in 2009-these changes are likely linked to past eutrophication events [29]. The abundance of Stuckenia pectinata, which is used as an indicator of lake quality has almost halved since 1975 [25]. Anecdotal evidence suggests that aquatic plants provide both ES, such as habitat and lake oxygenation but also have EDS relating to human recreation (e.g., decreasing the recreational opportunity of the lake for swimming and boat users (https: / / www.tdg.ch/geneve / chaleur-plantes-proliferent-leman/story/13368921 (accessed on 10 July 2020)), which may lead to contention between different user groups, and thus needs further investigation). The increasing abundance of aquatic plants currently warrants control, which is mandated by the state since the lake is a public good [28]. Management generally follows traditional methods and varies according to the species [28], but novel control solutions are being looked into, such as creating compost from aquatic plants (https: / / www.letemps.ch/sciences/compost-geant-plantes-algues-leman (accessed on 10 September 2020). Lake Léman remains highly important for transport, sports, recreation and tourism, water supply and fishing and is an important asset in the region, and therefore it is crucial to better understand and respond to environmental changes in and around the lake. 


\subsection{Study Approach}

Two approaches were used to collect data for this study: a semi-structured questionnaire survey to assess lake users' perceptions of environmental change and management in Lake Léman and in-depth key informant interviews. These approaches are complimentary; the semi-structured questionnaire approach allowed quantitative assessment of general trends in the case study region, whilst the key informant interviews explored the personal experiences of key individuals in more depth and allowed for the gathering of management related information.

Both the questionnaire and key-informant interviews took place during the COVID-19 pandemic; therefore, a mixed approach was taken to data collection using both in-person and online surveys and in-person or telephone interviews with key informants. The inperson questionnaires were administered with lake users in several towns and villages between Lutry and Gland during September 2020, targeting people that were engaged in activities in and around the lake (see Figure 1). For the online surveys, a 'snowballing' approach was used [30], which targeted lake user groups or societies, through their mailing lists and associated social media outlets. In total, 34 different user groups or societies were approached, including divers, recreational fishers, sailors, swimmers, rowers and motorboaters. The online version ran for two months during September and October 2020, using the program SurveyMonkey and included responses from people living across the whole lake region. Both the in-person and online questionnaires coincided with the end of a bloom event to allow for people to have recent experience of the aquatic plants over the summer. Major aquatic plant blooms take place in peak summer (June/July to September). A prototype version of the questionnaire was also piloted with 20 lake users before dissemination.

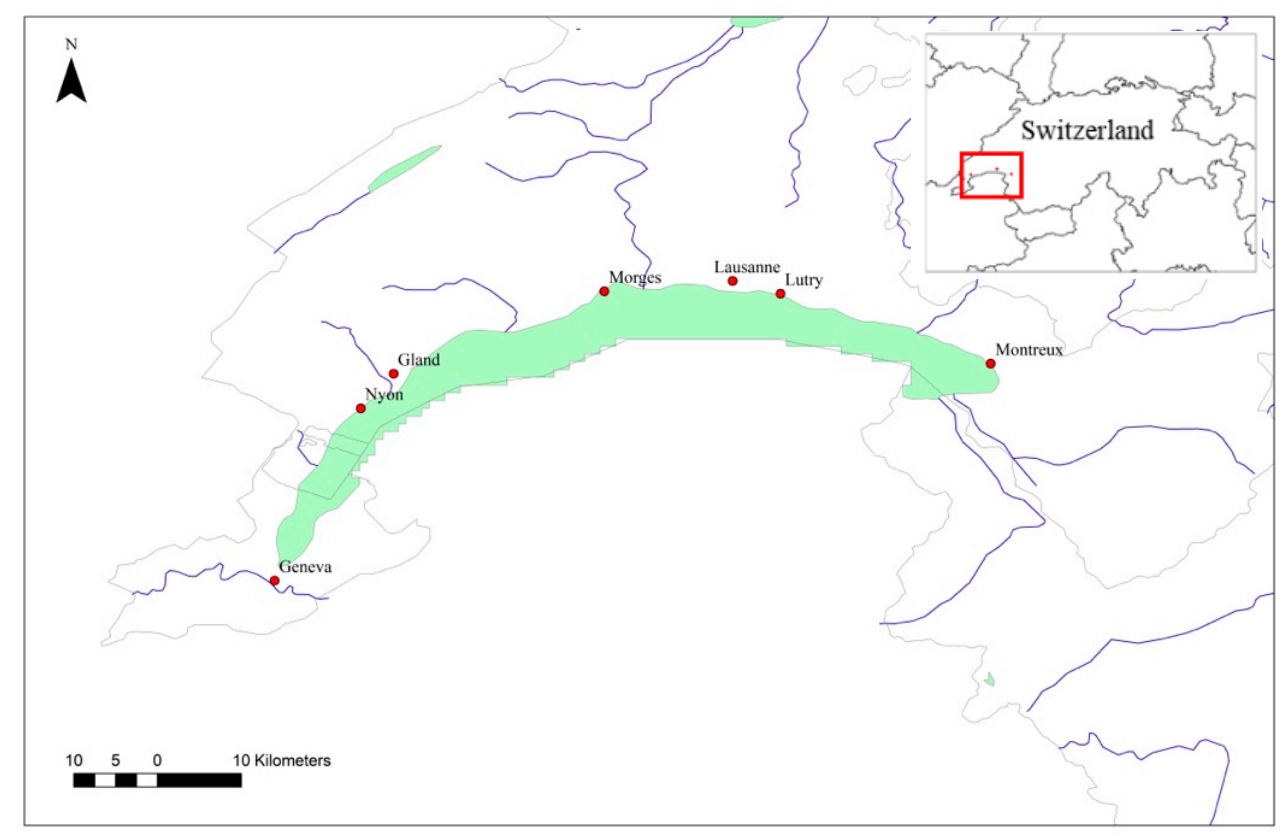

Figure 1. The study site depicting the region between Lutry and Gland in which the in-person questionnaires were administered with lake users.

The semi-structured questionnaire had five components: (1) type and frequency of lake use by respondents during the summer months (1 May-30 September) when aquatic plants are known to be abundant; (2) general perceptions of environmental change on the lake; (3) perceptions of aquatic plants in Lake Léman; (4) perceptions and willingness to pay for increased management of aquatic plants in the lake; and (5) social-demographic background information. Questionnaires were conducted in English or French. 
To determine general perceptions of environmental change in and around Lake Léman respondents were asked whether they perceived there to be any major environmental change in the lake over the last 10 years, and if yes, to outline what these changes had been. Respondents were also asked whether, in general, they perceived the lake environment to have improved, deteriorated or stayed the same, as well as to indicate their perceived threat level for the lake using a 5-point Likert scale $(1=$ not threatened at all, $5=$ very threatened). To elucidate perceptions on aquatic plants, respondents were asked to outline perceived abundance level using a Likert scale $(1=$ not abundant at all, $5=$ very abundant $)$ and whether aquatic plants had spread, stayed the same or decreased over the last 10 years. Respondents were also asked whether they perceived aquatic plants to have a positive or negative effect on people or the environment, and the type of effect (a free listing exercise). Finally, respondents were asked whether they thought the existing management of aquatic plants was effective, and if not, if they would be willing to pay for additional management. Respondents were also asked how they would want management efforts to be targeted. They were also able to provide additional comments at the end of the questionnaire.

Furthermore, seven key informant interviews were conducted with cantonal (regional) managers, lake-related NGOs, and people whose livelihoods are derived from the lake (including fishers, and those in the tourism and recreation industry) between September and October 2020. These interviews included broad-scale discussions of the lake, its management and the environmental changes taking place, and then focused on aquatic plants specifically and the effects they have.

\subsection{Data Analysis}

Only responses in the semi-structured questionnaire were used for statistical analysis. Differences in responses between online and in-person interviews were tested through a chisquared test $\left(\chi^{2}\right)$ of independence or Fisher's exact test (R package: MASS). In general, the respondent profiles and perceptions between in-person and online questionnaires were similar and no significant differences were found for most of the data. However, some very minor differences and biases were identified that are common in online questionnaire approaches (i.e., a tendency to have more educated respondents from online surveys ((as in our study $\left.\left(\chi^{2}=14.30, p<0.01\right)\right)$. Further, online respondents had a slightly higher interest in environmental issues and membership of environmental groups $(p<0.01$, Fisher's exact test) which is also another common bias. Due to the very minor differences in respondent profiles for online and in-person questionnaires, the data for the two was pooled for analysis.

To analyze user perceptions about the capacity of aquatic plants to provide ES or EDS, user groups were defined based on the recreational activities they regularly undertake associated with Lake Léman and whether this activity was primarily 'in the lake', e.g., swimming, scuba diving, 'on the lake', e.g., boating, sailing/windsurfing, rowing/kayaking/SUP, 'both', or 'by the lake', e.g., fishing, bird-watching, walking/running/ cycling, casual recreation near the lake. In addition, responses to questions on whether aquatic plants had a positive or negative effect on people or the environment in and around Lake Léman were categorized as perceived 'ES', 'EDS', 'both', or 'neither'. Chi-squared tests $\left(\chi^{2}\right)$ of independence were used to identify differences in types of recreational user and their perceptions of the capacity of aquatic weeds to provide ES or EDS. In addition, ES and EDS perceptions were explored to determine whether these were associated with perceptions of management need, using multinomial logit regression ( $R$ package: nnet). All statistical analysis was performed in R v.6.3.1 [31].

\section{Results}

\subsection{Characteristics of Respondents}

In total, 186 questionnaire responses were received: 127 from the online survey and 59 from in-person surveys along the side of the lake. In addition, the responses from the seven key informants were qualitatively drawn upon in order to illustrate the range of impacts caused by aquatic plants and specific management considerations. 
During the summer months (1 May-30 September), 39\% of respondents visited the lake two to three times a week, $17 \%$ visited the lake four to six times a week, and $24 \%$ visited the lake two to three times a month. Activities varied but respondents frequently reported undertaking multiple activities; swimming was the most popular activity (62\% of respondents reported swimming for fun, $30 \%$ reported swimming for exercise), followed by casual recreation on the lakeside, e.g., picnic, sunbathing (49\%) and boating (32\%). Only $20 \%$ of respondents lived in a lakeside property.

Most respondents had university-level education ( $56 \%$ indicated they had a postgraduate degree or equivalent diploma, and $28 \%$ indicated they had a Bachelor's degree or equivalent diploma). Most respondents (67\%) had a high interest in environmental issues; $44 \%$ watch or read environmentally related news a few times a month and $30 \%$ watch or read environmentally related news two to three times a week. Thirty-three percent of respondents indicated they were part of an environmental group. Most of the respondents were male $(67 \%)$ and middle aged.

\subsection{Observations of Environmental Change in Lake Léman}

Most respondents perceived that there had been a major environmental change within Lake Léman over the last 10 years. Of respondents that reported a major environmental change, $47 \%$ believed that overall, the lake environment had gotten worse, $33 \%$ believed it had gotten better, and the remainder $(20 \%)$ believed the lake had stayed generally the same or were unsure. One key informant expressed that since the control of major pollutants more than 10 years ago, algae and eutrophication have been reduced. As a result, water transparency has increased, aquatic plants have recolonized and new species have appeared. Another key informant suggested that "the lake is ever-changing and even in a single year lake cycles and quality can vary hugely". On a scale from not very threatened to very threatened, $46 \%$ of all respondents indicated that Lake Léman was moderately threatened and $31 \%$ reported the lake to be threatened.

Negative environmental changes mentioned were categorized into 13 broad factors (Table 1). The most common changes (reported by quarter of respondents) included an increase in the threat to fauna and an increase in invasive alien species (Table 1). The negative impacts of invasive alien species were described by several respondents, some of the species mentioned included Dreissena bugensis (quagga mussel), Silurus glanis (Wels catfish), Micropterus salmoides (largemouth bass) and Pacifastacus leniusculus (signal crayfish). Of respondents that mentioned invasive species as a negative impact, $63 \%$ mentioned "invasive mussel species" with reported impacts including "prevent algal growth", "decrease fish numbers", and "destroys spawning grounds". Native pest species mentioned were "fleas/duck lice", "cormorants", and "grey herons", with cormorants being the pest species most frequently reported by respondents $(80 \%)$. Cormorants were associated with fish depletion in the lake.

Macro (16\% of respondents) and micro (13\% of respondents) pollution was also noted as an issue (Table 1). Key pollutants mentioned included untreated sewage, microplastics, from car tires and different medical-related pollutants. Many respondents were knowledgeable about car tyre pollution as a report on this was publicized shortly before the questionnaires were conducted. Interestingly, some respondents suggested that due to COVID-19 policies (work-from-home, travel restrictions), many more people were using the lake, resulting in different types of disturbance, such as overcrowding and increased litter. Some respondents $(10 \%)$ suggested that natural water cycles and quality were being disturbed including the reduced flushing of cold bottom waters, and water deoxygenation, with many attributing this to aquatic plants and climate change. There is evidence to support this from long term lake monitoring by CIPEL. Eighteen percent of respondents view water temperature increase as a result of climate change to be a major emerging issue. 
Table 1. An overview of the negative and positive environmental changes listed by respondents. Note that percentages add up to more/less than 100 as many respondents mentioned more than/less than one negative or positive change. Only the responses from the semi-structured questionnaires were included in analysis.

\begin{tabular}{cccc}
\hline Negative Environmental Changes & \% of Respondents & Positive Environmental Change & \% of Respondents \\
\hline Fauna more threatened & 26 & Improved water quality & 22 \\
Increase in invasive alien species & 19 & Improved water clarity & 13 \\
Water temperature increase & 18 & Increase in biodiversity & Less micropollution \\
(climate change effects) & 16 & (including sewage) & Lower phosphorous levels \\
More macropollution & 15 & Less macropollution & 5 \\
Increase in pest species & 14 & & 5 \\
Increase in aquatic plants & 13 & More aquatic plants & Less algae \\
More micropollution & & \\
(including sewage) & 10 & \\
Increase in algae & 8 & \\
Mlterations to water cycling and quality & 7 & \\
Nutrient imbalances & 5 & \\
River flow changes & 5 & \\
Algae decrease & 2 & \\
Shore erosion and lakebed structural changes & 1 &
\end{tabular}

In total, eight different environmental factors were perceived to have improved by some respondents. The most common improvement was better water quality $(22 \%)$, followed by improved water clarity (13\%) (Table 1$)$. These two improvements were commonly attributed to better waste management (human waste and agricultural waste), in particular less sewage and phosphorous entering the lake. Some also link this to the presence of more aquatic plants, which is seen in a positive light by $(4 \%)$ of respondents. Several positive management actions were perceived to have contributed to positive environmental changes including increasing biodiversity levels in the lake. These include the "creation of protected areas", "better human waste management", "pumping stations for wastewater", "ban on water scooters", "improved awareness of litter management", "management of invasive plant species" and "actions of L'Association pour la Sauvegarde du Léman (an environmental NGO)".

\subsection{Aquatic Plants in Lake Léman}

Two thirds of respondents perceived aquatic plants in Lake Léman to be abundant or very abundant (Figure 2), furthermore, $63 \%$ of respondents believed that aquatic plant abundance has been increasing over the last 10 years (Figure 3). Most respondents attributed the increase in aquatic plants to climate change effects, although some also mentioned clearer water as a key factor driving this increase.

\subsection{Perceptions of Ecosystem Services (Benefits) of Aquatic Plants}

Sixty-one percent of respondents perceived that aquatic plants had at least one positive effect on people or the environment in and around Lake Léman. Only 16\% of respondents reported that aquatic plants had no positive effects. Key positive effects of aquatic plants included that they improved water regulation and habitat in the lake (47\%) and that they provided food for birds and fish (19\%) (Table 2). Various respondents and key informants recognized these values with statements such as "they are plants in the lake, they are natural and contribute to the environment" or "aquatic plants in the lake are useful for the fish and surely the ecosystem".

A minority of respondents, especially swimmers, believed the plants to be aesthetically pleasing. However, no significant difference was found between the type of lake user in relation to whether they perceived aquatic plants to have ES benefits, $\left(\chi^{2}=1.1703, p>0.05\right)$. 


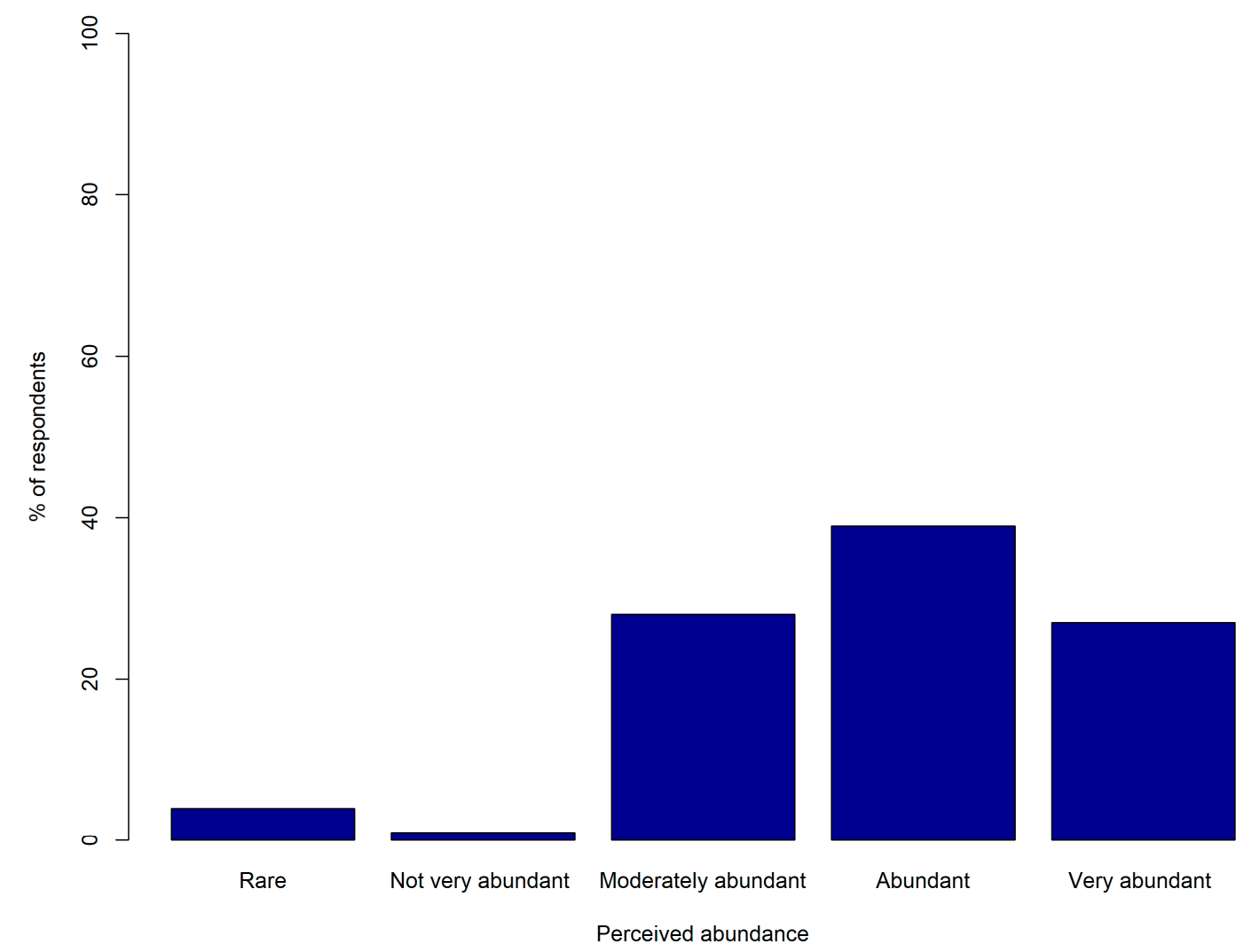

Figure 2. Perceived abundance of aquatic plants in Lake Léman.

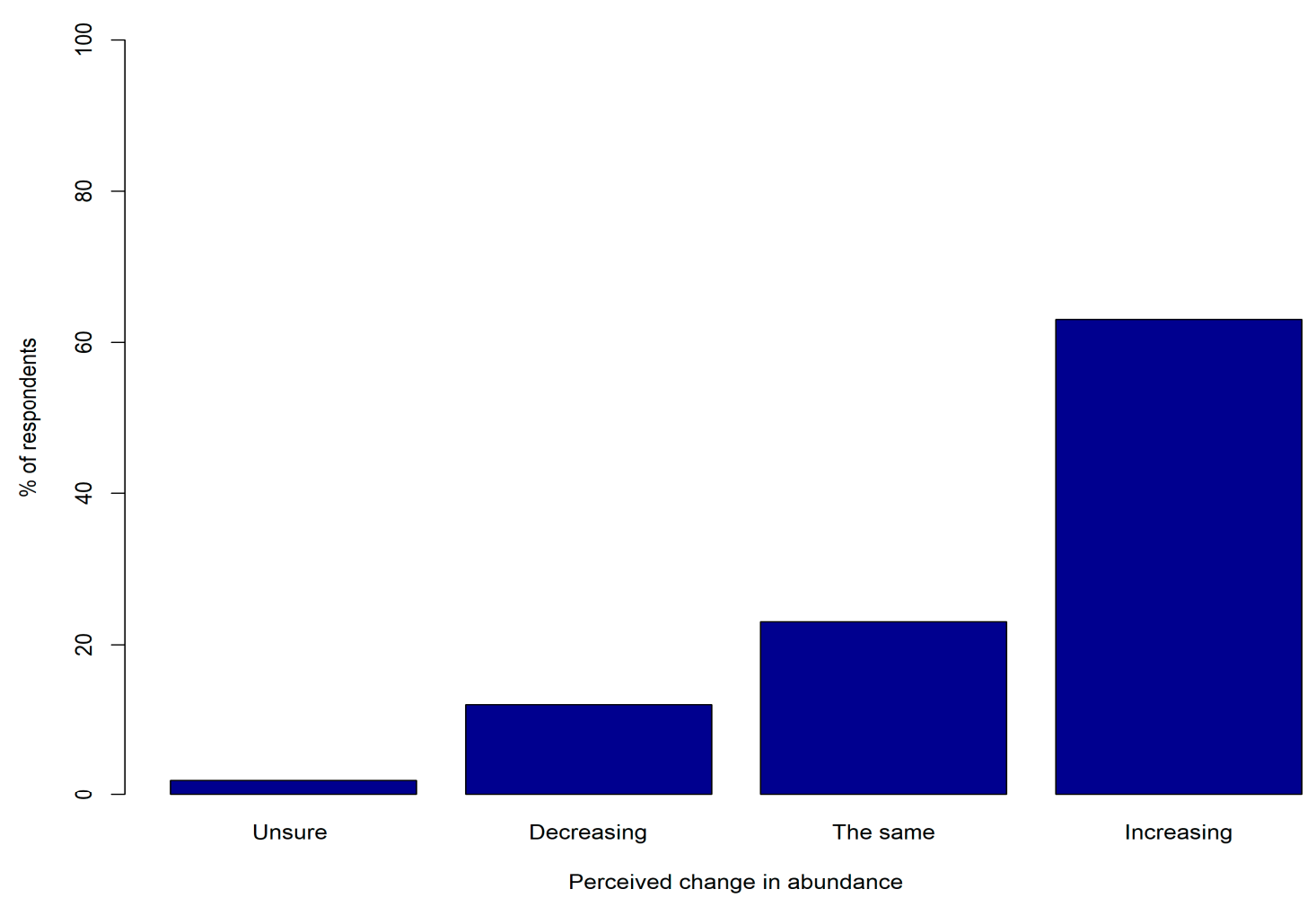

Figure 3. Perception of the change in abundance of aquatic plants in Lake Léman over the last 10 years. 
Table 2. Perceived benefits of aquatic plants categorized into various ecosystem service benefits (categorized based on TEEB, 2010 [32]). Note that percentages add up to more than 100 as many respondents mentioned more than one benefit. Only the responses from the semi-structured questionnaires were included in analysis.

\begin{tabular}{cc}
\hline Ecosystem Services & \% of Respondents \\
\hline Regulating/Supporting & \\
Improves water/ecosystem regulation (including purification, & 47 \\
oxygenation, water cycling, etc.) & 47 \\
Provides habitat for lake fauna & 5 \\
Promotes climate regulation & Provisioning \\
Provides food for birds and fish & Cultural \\
Aesthetically pleasing & 19 \\
\hline
\end{tabular}

\subsection{Perceptions of Ecosystem Disservices (Costs) of Aquatic Plants}

Broadly the EDS associated with the presence of aquatic plants in the lake could be categorized into five main EDS categories; physical and mental health and safety, economic, aesthetic or cultural, regulating/supporting and provisioning EDS (Table 3). The majority of respondents $(58 \%)$ perceived that aquatic plants had at least one negative effect on people or the environment in and around Lake Léman, with $21 \%$ of respondents believing that aquatic plants had no negative effects. Some respondents (13\%) viewed aquatic plants as a human safety risk, particularly for inexperienced swimmers who may get stuck in dense patches (Table 3). One respondent reported that "a friend almost drowned due to an accident (being tangled) with weeds in the lake". Another key informant expressed that "when people see them, they do not necessarily like them: the swimmers think it's disgusting, because they get their feet caught in it, and for the sailors/boaters it's the engines and it can be problematic". Similarly, some people (9\%) linked the presence of aquatic plants with an increase in duck lice, which can bite and cause major allergies, while a small number (3\%) perceived aquatic plants to be toxic or cause allergens.

Aquatic plants were viewed by $13 \%$ of respondents to cause minor damage to boats, mainly by jamming propellers. Some working in the tourism and the recreation industry reported an economic impact as a result of aquatic plants, either through equipment damage, physically impeding navigation, or by decreasing customer presence and satisfaction as people were put off recreation during aquatic plant blooms.

The main perceived impacts related to cultural and aesthetic EDS, with more than half of respondents (52\%) mentioning that aquatic plants impede recreation, and closely linking to this, they were viewed to impact navigation for boats (mentioned by $17 \%$ of respondents) (Table 3). To a lesser extent, aquatic plants were viewed as displeasing on several senses (unsightly, smells bad, feels bad). A key informant working on raising awareness about the values of these plants expressed that "most people do not see the beneficial aspect of these plants and only see them as something disgusting or disturbing their activities".

Several negative effects on supporting and regulating services were also mentioned (Table 3), with the primary one being that aquatic plants were perceived to result in lake deoxygenation, which was mentioned by $15 \%$ of respondents. Only one impact on provisioning services was mentioned, whereby $8 \%$ of respondents viewed the aquatic plants to reduce the number of fish. No significant difference was found between the type of lake user in relation to whether they perceived aquatic plants to be an $\operatorname{EDS}\left(\chi^{2}=1.1703, p>0.05\right)$.

\subsection{Management Considerations}

Despite most respondents recognizing the positive effects of the presence of aquatic plants in Lake Léman, the majority of respondents $(60 \%)$ indicated that aquatic plants should be managed to reduce their densities and negative effects (Figure 4). However almost a quarter (22\%) of respondents were unsure if aquatic plants should be managed. 
Interestingly, several respondents anecdotally mentioned that aquatic plants should not be managed for human benefit at the expense of the lake ecosystems or biodiversity. These responses suggested that aquatic plants should only be managed if they were causing ecological harm through their increasing abundance. One key informant in charge of aquatic plant management in the lake expressed that "there is more knowledge available now on how beneficial these plants are. We try to do the minimum maintenance, focusing on ports. On the banks we keep them. They are also cut in swimming areas".

Table 3. Perceived negative impacts of aquatic plants categorized into various ecosystem disservices based on Shackleton et al. (2016) [14] and this study. Note that percentages add up to more than 100 as many respondents mentioned more than one negative impact. Only the responses from the semi-structured questionnaires were included in analysis.

\begin{tabular}{|c|c|}
\hline Ecosystem Disservices & $\%$ of Respondents \\
\hline \multicolumn{2}{|l|}{ Physical and mental health and safety } \\
\hline Human safety risk & 13 \\
\hline Increases pests & 9 \\
\hline Toxicity and allergens & 3 \\
\hline \multicolumn{2}{|l|}{ Economic } \\
\hline Damages to boats, property or infrastructure & 18 \\
\hline Livelihood impacts (fishing and recreation) & 5 \\
\hline Induces extra management costs & 2 \\
\hline \multicolumn{2}{|l|}{ Aesthetic or cultural } \\
\hline Impedes recreation & 52 \\
\hline Impedes access and navigation & 17 \\
\hline Has a bad smell & 6 \\
\hline Creates an unpleasant feeling & 5 \\
\hline Is visually displeasing & 5 \\
\hline \multicolumn{2}{|l|}{ Regulating/supporting } \\
\hline Causes deoxygenation & 15 \\
\hline Promotes eutrophication/more algae & 8 \\
\hline Alters light levels & 5 \\
\hline Facilitates biological invasions & 3 \\
\hline Over filtration & 2 \\
\hline Induces ecosystem changes (unspecified) & 2 \\
\hline Leads to water quality changes & 1 \\
\hline \multicolumn{2}{|l|}{ Provisioning } \\
\hline Decreases fish & 8 \\
\hline
\end{tabular}

People's support for management was correlated with their perception of ES or EDS $(p<0.001, \mathrm{df}=6, \mathrm{dev}=27.3)$. Respondents that perceived that aquatic plants were associated with both the provision of ES and EDS were significantly more likely to report that plants should be managed $(p$-value $<0.01)$ than indicate that aquatic plants should not be managed. Conversely, respondents that reported that aquatic plants were only associated with ES provision were significantly more likely to indicate that plants should not be managed ( $p$-value $<0.01$ ), or that they were unsure as to management $(p$-value $<0.01$ ). There was no significant association between respondents that indicated that aquatic plants only provided EDS or neither ES or EDS and the type of management reported.

There was a lot of uncertainty in perceptions regarding whether the current management of aquatic weeds in the lake was deemed effective (i.e., $56 \%$ of respondents indicated they were unsure if management was effective). Approximately a quarter $(26 \%)$ of respondents perceived management to be ineffective and $17 \%$ indicated that current management was effective. It was noted by a few respondents and key informants that some of the current machinery used for managing aquatic plants in the lake is old and inefficient and new technology and approaches need to be investigated.

Just under half of all respondents (44\%) indicated that they would be willing to pay additional finances to cover the costs of increased management/removal of aquatic plants in some parts of Lake Léman. Amongst respondents willing to pay for increased manage- 
ment/removal, 63\% indicated they would hypothetically prefer to pay this as additional $\operatorname{tax}, 23 \%$ as a donation and $13 \%$ as an entrance fee to a cleared area. For the majority of respondents that reported they were not prepared to pay additional finances to cover management/removal costs $(53 \%)$, the main reason for this was that "management should be included in tax payments already" or that management is not needed. Suggestions on where additional management/removal actions should be directed included in "areas most frequented", "swimming locations", "boat launch areas", "channels for boats", "biodiversity hotspots and nature reserves", and "shallow bays". One respondent indicated that "management should be directed at locations where high densities of aquatic plants correspond with high densities of duck lice". Another reported that "the current management - through mowing - must be done intelligently, at the right time, to avoid the large masses of aquatic plants that are found everywhere throughout the lake. Currently, management is rather ineffective; aquatic plants are ineffectively removed after mowing and it is not efficient". Several respondents were in favor of management in certain areas (e.g., beaches and ports) but indicated that it was important to leave some areas untouched.

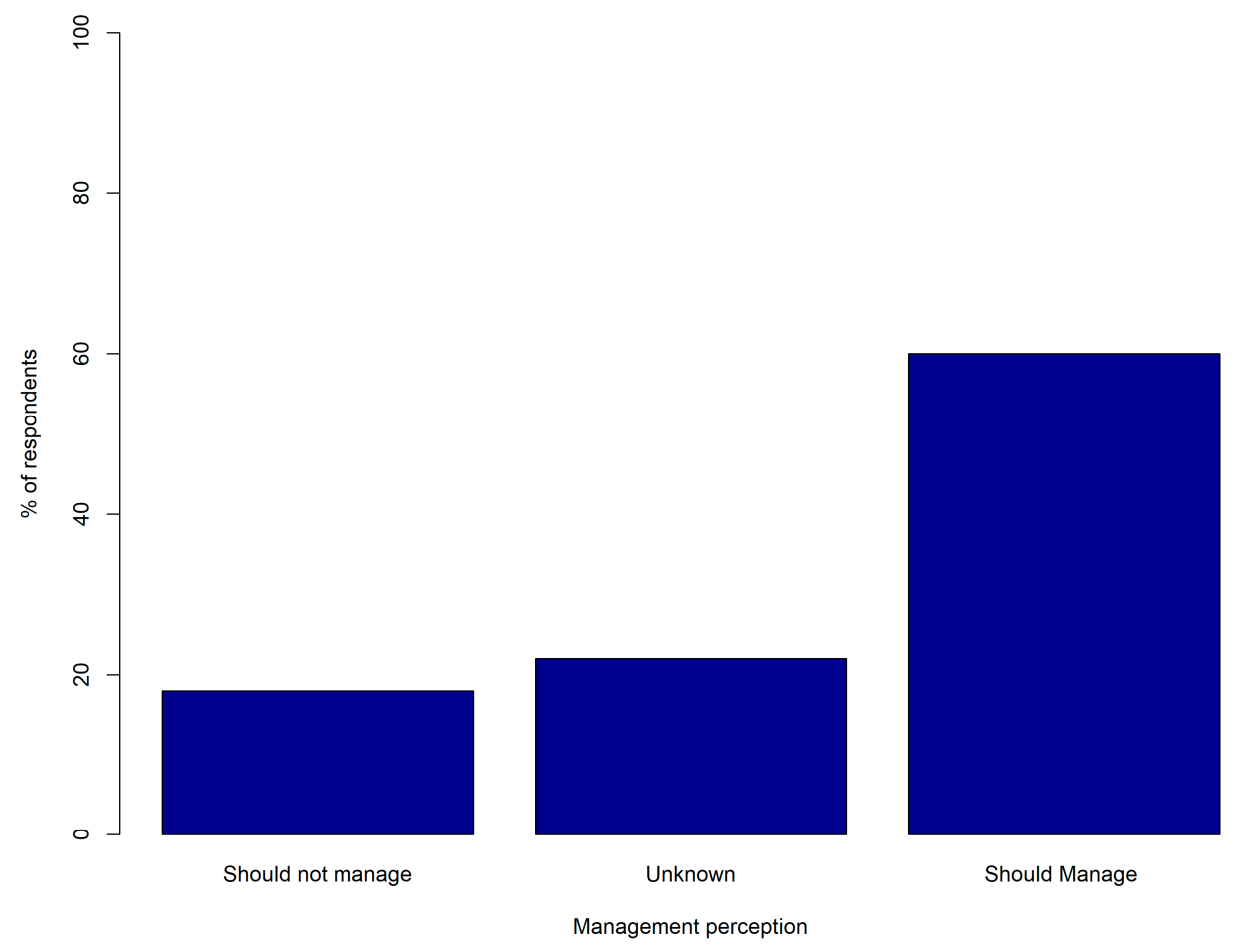

Figure 4. Perception of whether management of aquatic plants should be implemented in Lake Léman.

Few respondents $(24 \%)$ had seen published information on the aquatic plants of Lake Léman. Although respondents were not specifically asked about their interest in engaging with management in the questionnaire, in the option to add any comments and in further discussions through in-person interviews and with key informants, several people indicated their interest in getting involved with helping to monitor and manage negative environmental changes in the lake through volunteering and citizen science initiatives. This included one key informant involved in managing an open water swimming community on Lake Léman and another in a scuba diving club.

\section{Discussion}

Our study highlights the importance of considering the linkages between social perceptions and the environment when making management decisions. It shows that people who use the Lake Léman environment are relatively aware of the changes that take place (Table 1) and have strong, albeit conflicting, opinions with regards to how the management of natural resources should occur. Broadly, lake users' perceptions of 
environmental change correspond quite closely with scientific evidence from regular longterm scientific monitoring and reporting of numerous variables in the lake yearly since 1969 (see annual reports here https:/ / www.cipel.org/publications/rapports-scientifiques/ accessed on 10 March 2021; much of which is promoted to broader audiences through the popular press). The major changes identified in our study (e.g., pollution, invasive species, increasing aquatic plants and more) are similar to the main environmental change issues identified by lake users in perception-based studies undertaken in other regions of the world $[33,34]$. Although, some interesting points raised by respondents such as "aquatic plants cause deoxygenation of the lake" and "reduce fishing" do lack empirical evidence and should be better quantified through more research and monitoring.

It is evident from our study that most respondents are acutely aware of the diversity of ES and EDS that are associated with the presence of aquatic plants in Lake Léman and the effects they have on people and the environment (Tables 2 and 3). The findings of our study indicate that recreation in particular, is heavily impacted by the abundance of aquatic plants in the lake, mostly during periods of heavy blooming which occurred just prior to the dissemination of our questionnaire in 2020. The times of heavy blooming also coincide with high use levels of the lake during the summer months. This is important since, in addition to potential economic costs experienced by reduced recreational activity and associated management, previous studies have shown that recreational benefits are closely linked to less tangible cultural ES, such as spiritual and experiential values and health benefits [35], which may also be indirectly impacted by reduced access to recreation when aquatic plant density is high. This is an important area for future research since a greater understanding of the interactions between different categories of ES is required for more holistic management of ecosystems [36].

Conversely, the most commonly perceived ES provided by aquatic plants relate to provisioning/supporting services, primarily water regulation and providing habitat for aquatic organisms. The societal perception of benefits is important since this is thought to be linked to enhanced uptake of biodiversity conservation and management efforts [1]. The majority of respondents interviewed in this study recognized the potential positive impacts of aquatic plants in the lake, but we cannot fully disentangle if this is due to their personal experience or based on scientific information they have read, and it is likely to be a combination of both. However, it is interesting that where respondents recognized ES and EDS provision, they remain significantly more likely to favor management of aquatic plants, suggesting that people prefer to manage against the generation of EDS rather than enhancement of the provision of ES, particularly in places that affect recreational use.

Further empirical evidence is needed to better understand the effects of increasing aquatic plants in the lake environment, and the optimal densities of aquatic plants that maximize ES and minimize EDS. This information could then be used to communicate more effectively with stakeholders on needed or existing management actions. Further, stakeholder engagement initiatives should be implemented to understand user needs and to mitigate potential conflicts around management and to promote co-management [37,38].

Our study contributes further empirical evidence to a limited but growing body of research assessing the implications of aquatic plant blooms on people and the environment, which have previously focused mainly on invasive water weeds [17]. Through assessing perceptions of environmental change in Lake Léman held by key stakeholders, the need for further work on the topic was identified. For example, to our knowledge, there have been limited studies on the long-term and wide-scale changes in aquatic plant abundance on the lake on a large scale (e.g., using plots to assess aquatic plant composition) [27,29]. More research on this, possibly drawing on remote sensing tools [39,40], would be highly useful to contribute further to discussions about the broad scale changes taking place (i.e., are blooms becoming more frequent, denser and lasting longer?). Further, quantifying people's perceived impacts as a result of aquatic plant proliferation would be useful especially as the evidence is less conclusive on some of these points, e.g., if aquatic plant proliferation leads to reduced fish abundance and what optimal densities are [41-43], if they cause 
deoxygenation or not [44], or if aquatic plants lead to increased populations of duck lice. In addition, quantifying the economic impacts of aquatic bloom events on ES provision, particularly tourism and recreation, will improve assessment of how environmental change and plant abundance can affect ecosystem value [45]. Revealed preference data that assesses how recreational activity and visitation patterns are affected by the increased abundance of aquatic plants can be used to assess economic losses during bloom events [46].

Our study provides a window into the experiences of key actor groups that regularly use and are affected by the presence of aquatic plants in the lake and indicates that there is interest and knowledge on where and how management should be carried out. Inferences gained from our work could help local managers to prioritize the management of aquatic plants in the lake environment. For example, although most respondents were in favor of managing aquatic plants, many were sensitive to the need to balance management actions to ensure that EDS were mitigated but not at the expense of ES provision and biodiversity. As such, suggestions on where management should be directed were focused on areas where weeds heavily impacted human activities, ensuring that protected sites remain untouched (unless aquatic plant blooms had negative implications for biodiversity in these areas). Management planning efforts should be further substantiated with participatory planning initiatives to guide effectiveness and overall social benefit [47]. Through this work, it was found that many groups were also interested in participating in citizen science initiatives, which could be set up to help with long-term monitoring and control of environmental change issues in Lake Léman, but also other lakes in Switzerland and globally. Citizen science initiatives have been used with great success for monitoring different types of environmental changes in other lakes around the world [48-50] and should be considered more in Switzerland. There are several established lake-related NGOs, associations and societies which could become involved and help facilitate such initiatives.

Author Contributions: L.E.W. and R.T.S. conceived the initial idea. L.E.W., R.T.S., M.Z.A., C.A.K. contributed to the design of the methodology (survey) and helped to collect data. L.E.W. and J.G. analyzed the data. L.E.W. and R.T.S. co-wrote the first draft of the paper with further input from all authors. All authors have read and agreed to the published version of the manuscript.

Funding: This research received no external funding.

Institutional Review Board Statement: The University of Lausanne, at which the project originated, did not yet have an ethics review board at the time this research was initiated. This research is considered low risk and all participants gave prior, informed consent, consistent with established principles in the Swiss Data Protection Act 1992, and confirmed they were over 18 years of age.

Informed Consent Statement: Informed consent was obtained from all subjects involved in the study.

Acknowledgments: We thank Su Su Myat, and Elina Mourtazina for their inputs into this work. We thank all the society managers and heads who distributed the survey, especially Tim Davis the Chairman of the Lake Geneva Swimming Association who went the extra mile. We thank all the questionnaire respondents and key informants who participated in the study for their time and interest.

Conflicts of Interest: The authors declare no competing financial interests.

\section{References}

1. Bennett, N.J. Using perceptions as evidence to improve conservation and environmental management. Conserv. Biol. 2016, 30, 582-592. [CrossRef] [PubMed]

2. Schermerhorn, J.R.; Hunt, J.; Osborn, R.N. Organizational Behaviour; Wiley and Sons: New York, NY, USA, 2000.

3. Shackleton, R.T.; Richardson, D.M.; Shackleton, C.M.; Bennett, B.; Crowley, S.L.; Dehnen-Schmutz, K.; Estévez, R.A.; Fischer, A.; Kueffer, C.; Kull, C.A.; et al. Explaining people's perceptions of invasive alien species: A conceptual framework. J. Environ. Manag. 2019, 229, 10-26. [CrossRef] [PubMed]

4. Whyte, A.V.T. Guidelines for field studies in environmental perception. In MAB Technical Notes No. 5; UNESCO: Paris, France, 1977; p. 118.

5. Weber, E.U. Experience-based and description-based perceptions of long-term risk: Why global warming does not scare us (yet). Clim. Chang. 2006, 77, 103-120. [CrossRef] 
6. Turner, B.L., II; Esler, K.J.; Bridgewater, P.; Tewksbury, J.; Sitas, N.; Abrahams, B.; Chapin, F.S., III; Chowdhury, R.R.; Christie, P.; Díaz, S.; et al. Socio-Environmental Systems (SES) Research: What have we learned and how can we use this information in future research programs. Curr. Opin. Environ. Sustain. 2016, 19, 160-168. [CrossRef]

7. Dudley, N.; Higgins-Zogib, L.H.; Hockings, M.; MacKinnon, K.; Sandwith, T.; Stolton, S. National parks with benefits: How protecting the planet's biodiversity also provides ecosystem services. Solutions 2011, 2, 87-95.

8. La Rosa, D.; Spyra, M.; Inostroza, L. Indicators of cultural ecosystem services for urban planning: A review. Ecol. Indic. 2016, 61, 74-89. [CrossRef]

9. Ament, J.M.; Moore, C.A.; Herbst, M.; Cumming, G.S. Cultural ecosystem services in protected areas: Understanding bundles, trade-offs, and synergies. Conserv. Lett. 2017, 10, 440-450. [CrossRef]

10. Sagie, H.; Morris, A.; Rofè, Y.; Orenstein, D.E.; Groner, E. Cross-cultural perceptions of ecosystem services: A social inquiry on both sides of the Israeli-Jordanian border of the Southern Arava Valley Desert. J. Arid Environ. 2013, 97, 38-48. [CrossRef]

11. Yang, Y.E.; Passarelli, S.; Lovell, R.J.; Ringler, C. Gendered perspectives of ecosystem services: A systematic review. Ecosyst. Serv. 2018, 31, 58-67. [CrossRef]

12. Turner, R.K.; Morse-Jones, S.; Fisher, B. Ecosystem valuation, a sequential decision support system and quality assessment issues. Ann. N. Y. Acad. Sci. 2010, 1185, 79-101. [CrossRef]

13. Hamman, H.; Biggs, R.; Reyers, B. An exploration of human wellbeing bundles as identifiers of ecosystem service use patterns. PLoS ONE 2016, 11, e0163476. [CrossRef]

14. Shackleton, C.M.; Ruwanza, S.; Sanni, G.S.; Bennett, S.; De Lacy, P.; Modipa, R.; Mtati, N.; Sachikonye, M.; Thondhlana, G. Unpacking Pandora's box: Understanding and categorizing ecosystem disservices for environmental management and human wellbeing. Ecosystems 2016, 19, 587-600. [CrossRef]

15. Vaz, A.S.; Kueffer, C.; Kull, C.A.; Richardson, D.M.; Vicente, J.R.; Kühn, I.; Schröter, M.; Hauck, J.; Bonn, A.; Honrado, J.P. Integrating ecosystem services and disservices: Insights from plant invasions. Ecosyst. Serv. 2017, 23, 94-107. [CrossRef]

16. Reynaud, A.; Lanzanova, D. A global meta-analysis of the value of ecosystem services provided by lakes. Ecol. Econ. 2017, 137, 184-194. [CrossRef] [PubMed]

17. Keller, R.P.; Masoodi, A.; Shackleton, R.T. The impact of invasive aquatic plants on ecosystem services and human wellbeing in Wular Lake, India. Reg. Environ. Chang. 2018, 18, 847-857. [CrossRef]

18. United Nations Environment Programme. Global Environment Outlook Year Book: An Overview of Our Changing Environment; United Nations Environment Programme: Nairobi, Kenya, 2012.

19. Suk, J.E.; Vaughan, E.C.; Cook, R.G.; Semenza, J.C. Natural disasters and infectious disease in Europe: A literature review to identify cascading risk pathways. Eur. J. Public Health 2019, 30, 928-935. [CrossRef]

20. Chamot, E.; Toscani, L.; Rougemont, A. Public health importance and risk factors for cercarial dermatitis associated with swimming in Lake Leman at Geneva, Switzerland. Epidemiol. Infect. 1998, 120, 305-314. [CrossRef]

21. Perroud, M.; Goyette, S. Impact of warmer climate on Lake Geneva water-temperature profiles. Boreal Environ. Res. 2010, 15, $255-278$.

22. Lods-Crozet, B. Long-term biomonitoring of invertebrate neozonas in Lake Geneva. Arch. Sci. 2014, 67, 101-108.

23. Bouffard, D.; Dami, J.; Schmid, M. Swiss Lake Temperature Monitoring Program; Report Commissioned by the Federal Office for the Environment (FOEN); Eawag: Kastanienbaum, Switzerland, 2019.

24. Lane, S.N.; Bakker, M.; Costa, A.; Girardclos, S.; Loizeau, J.L.; Molnar, P.; Silva, T.; Stutenbecker, L.; Schlunegger, F. Making stratigraphy in the Anthropocene: Climate change impacts and economic conditions controlling the supply of sediment to Lake Geneva. Sci. Rep. 2019, 9, 1-11. [CrossRef]

25. CIPEL (Commission Internationale pour la Protection des eaux du Léman contre la Pollution). Sur les Etudes et Recherches Entreprises dans le Basin Lémanique; CIPEL: Nyon, Switzerland, 2019.

26. Anneville, O.; Pelletier, J.P. Recovery of Lake Geneva from eutrophication: Quantitative response of phytoplankton. Archiv für Hydrobiologie 2000, 148, 607-624. [CrossRef]

27. Labat, F. Macrophytes et moules invasives du Leman. Rapp. Comm. Int. Prot. Eaux Léman Contre Pollut. Camp. 2019, 2020, 206-210.

28. République et Canton de Genève. Rives Genevoises du Leman: Plan de Gestion pour le Faucardage des Plantes Aquatiques; Mise a Jour du Rapport; GREN Biologgie Appliquée Sàrl: Genève, Switzerland, 2008.

29. Perfetta, J. Étude de la végétation macrophytique du Léman (macrophytes of Lake Geneva). Rapp. Comm. Int. Prot. Eaux Léman Contre Pollut. Camp. 2010, 2011, 141-142.

30. Babbie, E. The Basics of Social Research; Wadsworth Cengage Learning: Belmont, CA, USA, 2010.

31. R Core Team. R: A language and environment for statistical computing; R Foundation for Statistical Computing: Vienna, Austria, 2020; Available online: https:/ / www.R-project.org/ (accessed on 10 March 2020).

32. TEEB. The Economics of Ecosystems and Biodiversity Ecological and Economic Foundations; Kumar, P., Ed.; Earthscan: London, UK; Washington, DC, USA, 2010.

33. Beardmore, B. Boater perceptions of environmental change issue affecting lakes in Northern Wisconsin. J. Am. Water Resour. Assoc. 2015, 51, 537-549. [CrossRef]

34. Nanayakkara, L.; Wissel, B. Preliminary investigation of lake-use patterns in prairie lakes, stakeholder perceptions, and resulting management implications. Lake Reserv. Manag. 2017, 33, 49-61. [CrossRef]

35. Bryce, R.; Irvine, K.N.; Church, A.; Fish, R.; Ranger, S.; Kenter, J.O. Subjective wellbeing indicators for large-scale assessment of cultural ecosystem services. Ecosyst. Serv. 2016, 21, 258-269. [CrossRef] 
36. Reed, M.S. Stakeholder participation for environmental management: A literature review. Biol. Conserv. 2008, 141, 2417-2431. [CrossRef]

37. Novoa, A.; Shackleton, R.; Canavan, S.; Cybele, C.; Davies, S.J.; Dehnen-Schmutz, K.; Fried, J.; Gaertner, M.; Geerts, S.; Griffiths, C.L.; et al. A framework for engaging stakeholders on the management of alien species. J. Environ. Manag. 2018, 205, 286-297. [CrossRef]

38. Bartsch, I.; Tittley, I.; Thiemann, S.; Hennig, B.D.; Cogan, C.; Kuhlenkamp, R. Macrophyte monitoring by hyperspectral remote sensing and ground based biotope mapping a tool to assist the monitoring demands of the EU-water frame work directive? In Proceedings of the MarBEF Workshop: 'How to Detect Changes in Biodiversity-Concepts, Methods and Tools', Banyuls, France, 2-4 February 2005.

39. Valta-Hulkkonen, K.; Kanninen, A.; Pellikka, P. Remote sensing and GIS for detecting changes in the aquatic vegetation of a rehabilitated lake. Int. J. Remote Sens. 2004, 25, 5745-5758. [CrossRef]

40. Villa, P.; Pinardi, M.; Bolpagni, R.; Gillier, J.M.; Zinke, P.; Nedelcuţ, F.; Bresciani, M. Assessing macrophyte seasonal dynamics using dense time series of medium resolution satellite data. Remote Sens. Environ. 2018, 216, 230-244. [CrossRef]

41. Grenouillet, G.; Pont, D.; Seip, K.L. Abundance and species richness as a function of food resources and vegetation structure: Juvenile fish assemblages in rivers. Ecography 2002, 25, 641-650. [CrossRef]

42. Dibble, E.D.; Pelicice, F.M. Influence of aquatic plant-specific habitat on an assemblage of small neotropical floodplain fishes. Ecol. Freshw. Fish 2010, 19, 381-389. [CrossRef]

43. Ismail, S.N.; Abd Hamid, M.; Mansor, M. Ecological correlation between aquatic vegetation and freshwater fish populations in Perak River, Malaysia. Biodiversitas J. Biol. Divers. 2018, 19, 279-284. [CrossRef]

44. Caraco, N.; Cole, J.; Findlay, S.; Wigand, C. Vascular plants as engineers of oxygen in aquatic systems. BioScience 2006, 56, 219-225. [CrossRef]

45. Shiferaw, H.; Bewket, W.; Alamirew, T.; Zeleke, G.; Teketay, D.; Bekele, K.; Schaffner, U.; Eckert, S. Implications of land use/land cover dynamics and Prosopis invasion on ecosystem service values in Afar Region, Ethiopia. Sci. Total Environ. 2019, 675, 354-366. [CrossRef]

46. Landry, C.E.; Bergstrom, J.; Salazar, J.; Turner, D. How has the COVID-19 Pandemic affected outdoor recreation in the US? A revealed preference approach. Appl. Econ. Perspect. Policy 2020. [CrossRef]

47. Nygrén, N.A. Scenario workshops as a tool for participatory planning in a case of lake management. Futures 2019, 107, 29-44. [CrossRef]

48. Sarnelle, O.; Morrison, J.; Kaul, R.; Horst, G.; Wandell, H.; Bednarz, R. Citizen monitoring: Testing hypotheses about the interactive influences of eutrophication and mussel invasion on a cyanobacterial toxin in lakes. Water Res. 2010, 44, 141-150. [CrossRef]

49. Canfield, D.E., Jr.; Bachmann, R.W.; Stephens, D.B.; Hoyer, M.V.; Bacon, L.; Williams, S.; Scott, M. Monitoring by citizen scientists demonstrates water clarity of Maine (USA) lakes is stable, not declining, due to cultural eutrophication. Inland Waters 2016, 6, 11-27. [CrossRef]

50. Thornhill, I.; Chautard, A.; Loiselle, S. Monitoring biological and chemical trends in temperate still waters using citizen science. Water 2018, 10, 839. [CrossRef] 